Article

\title{
Photocatalysis as a Tool for in Vitro Drug Metabolism Simulation: Multivariate Comparison of Twelve Metal Oxides on a Set of Twenty Model Drugs
}

\author{
Maciej Gawlik®D, Jakub Trawiński and Robert Skibiński *(D) \\ Department of Medicinal Chemistry, Medical University of Lublin, Jaczewskiego 4, 20-090 Lublin, Poland; \\ maciej.gawlik@umlub.pl (M.G.); jakub.trawinski@umlub.pl (J.T.) \\ * Correspondence: robert.skibinski@umlub.pl; Tel.: +48-81-4487390; Fax: +48-814-487-380
}

Received: 2 December 2019; Accepted: 22 December 2019; Published: 25 December 2019

\begin{abstract}
The constant development in the area of medicinal substances on the market and their subsequent progress in the field of drug analysis has become one of the reasons for the search for alternative, cheaper, and faster methods to determine the metabolism pathways of new molecular entities (NMEs). The simulation of transformation processes using photocatalysis is considered to be one of the promising methods. Although its effectiveness has been proven, the research has so far focused especially on titanium dioxide, while a more accurate comparison of the suitability of different photocatalysts in terms of their use in drug metabolism studies has not been performed. For this purpose, a set of twelve metal oxides was prepared and their photocatalytic efficiency in the direction of drug metabolism mimicking was checked on a model mixture of twenty medicinal substances differing both in chemical structure and pharmacological properties. Incubation with human liver microsomes (HLMs) was used as the reference method. The metabolic profiles obtained with the use of LC-MS analysis were compared using multidimensional chemometric techniques; and the graphic presentation of the results in the form of PCA plot and cluster dendrogram enabled their detailed interpretation and discussion. All tested photocatalysts confirmed their effectiveness. However, the exact outcome of the study indicate advantage of the $\mathrm{WO}_{3}$-assisted photocatalysis over other metal oxides.
\end{abstract}

Keywords: photocatalysis; metabolism study; PCA; HCA; mass spectrometry; HLM

\section{Introduction}

Heterogeneous photocatalysis is a type of photochemical reaction accelerated by the presence of the catalyst particle in a different phase from the reactants. The discovery of this phenomenon has marked the beginning of its versatile use in the various fields of science and the interest in the subject is reflected in a large number of reports [1]. It is assumed that the water-splitting experiment with the use of titanium dioxide made by Fujishima and Honda in 1972 was a breakthrough in the context of this technique development [2,3]. This extraordinary finding made it possible to obtain hydrogen by eco-friendly and cost-effective method and became also a promising announcement of its further use. The unique properties of this material became also the basis of its significant application especially in environmental area [4-6]. Particularly noteworthy is the use of $\mathrm{TiO}_{2}$ nanoparticles for the air decontamination and water purification where its ability in organic compounds degrading supports pesticides and other hazardous materials residuals removal [7-11]. Titanium dioxide has also medical application while being known as an effective microbiological sterilizing agent [12-15]. Moreover, it has recently become the subject of research on the use in new cancer treatment strategies [16]. 
The mechanism of action of photocatalysts includes their properties as a semiconductor. The absorption of photon energy equal or greater than their band gap results in electron excitation from a valence to a conduction band, generating an electron-hole pair in the valence band. The photogenerated holes can react with adsorbed water molecules forming hydroxyl radical $\left({ }^{\bullet} \mathrm{OH}\right)$ which is known as a powerful oxidizing agent. The additional presence of oxygen in a reaction environment results in superoxide anion radical $\left(\mathrm{O}_{2}{ }^{\bullet-}\right)$ formation due to its electron scavenging activity. The following chain reactions lead to formation of other reactive oxygen species (ROS). The unpaired electron of radicals with simultaneous strong reductive-oxidizing potential determines further advanced oxidation processes (AOPs) which can occur in any organic and inorganic compound present in the reaction environment [17]. Among the ideal attributes of the photocatalyst, both chemical and biological inertness, photostability and availability with low cost and toxicity are the most often mentioned [18]. Titanium dioxide is characterized by many of these properties, however it has also some limitations in use. According to the Planck equation, the band gap energy of this semiconductor $(\sim 3.2 \mathrm{eV}-$ for anatase phase) allows for the absorption of radiation only below $400 \mathrm{~nm}$, causing a lack of use of the remaining spectrum of sunlight $[19,20]$. The efforts to eliminate the significance of this problem have resulted in numerous reports of effective attempts to modify structurally titanium dioxide and attempts to use admixtures of other compounds and substances [21-25]. Despite the fact that $\mathrm{TiO}_{2}$ is a photocatalyst with the best-known properties and the widest application, other compounds are also gaining importance in the course of photocatalytic methods development. It is worth mentioning that zinc oxide is found to be the second most used photocatalyst due to its low-toxic, photostability and high photoreactive nature [26,27]. Zinc oxide has been the subject of many studies in which it showed even greater efficiency in relation to titanium dioxide $[28,29]$. It has been also shown that other photocatalysts, such as iron(II) oxide and tungsten(VI) oxide, are able to produce ROS in conditions of irradiation with the range of visible light and its photocatalytic efficiency can also be improved by using admixtures [30-32]. A wide range of photocatalysts and significant differences in their properties indicate a continuous need to look for the most ideal one with regard to its use.

The ability to decompose organic compounds under the influence of irradiation with appropriate energy has initiated the use of photocatalysts in the simulation of drug metabolism processes [33-41]. The ability to produce reactive oxygen species entering redox reactions with medicine molecules allows to mimic the biochemical reactions that the drug undergoes after administration to the patient. It was confirmed that the transformation products obtained by photocatalytic approach coincide structurally with metabolites, and the efficiency and speed of this method constitute one of its benefits. The obtained, promising results became the basis for further developing this simulation method. The understanding of the routes of drug metabolism is crucial due to possibility of toxic and reactive intermediates occurrence which may have a strong negative impact on patient health [42-44]. The discovery of such properties of the drug in the advanced phase of its development means enormous costs for the pharmaceutical companies [45]. For this reason, the method that engages relatively low human resources and additionally is simple and fast is highly desirable. The studies carried out so far has focused on the use of titanium dioxide for this purpose, although recent reports indicate the possible advantage of the other photocatalysts in the simulation of drug metabolism [46,47].

The obtained results allow for an initial assessment of the suitability of the method, but do not give a broader view on the selection of the most efficient photocatalyst allowing to register the metabolic profile as similar as the natural one. In addition, the results of tests conducted on a single drug substance are also the reason for the small amount of data to be compared. In order to select the most suitable photocatalyst for the study of drug metabolism, a set of twenty model pharmaceuticals with a diverse chemical structure were used and the selection substances was limited to compounds undergoing hepatic metabolic pathway. A set of twelve photocatalysts was chosen, among which were compounds of confirmed and previously undocumented effectiveness. As a reference method, the incubation with human liver microsomes (HLM) was used, and then the obtained metabolic profiles were multivariate compared. Advanced chemometric methods, including PCA (principal component 
analysis) and HCA (hierarchical cluster analysis), were used to differentiate selected photocatalysts in terms of their use and suitability in further drug metabolism research.

\section{Results and Discussion}

The process of establishing the metabolic pathway of pharmaceutical substances transformation is one of the important elements of introducing new molecular entity (NME) for widespread use in medicine. The development of techniques allowing for a quick and uncomplicated determination of drug transformation products is based on an intensive increase in the number of designed and directed to the preliminary clinical trials, medicinal compounds. For this reason, their ability in organic substances decomposition has become a reason for the considering of metal oxides use in developing a method that allows for one to obtain intermediate products of the biological drug transformation process. The concentration a lot of attention in these studies on the use of titanium dioxide and the search for another compound with a better fit to the profile of conducted studies is also significant. Despite the fact that the photocatalysis process is successfully used in the simulation of the drug metabolism, a broader comparison assuming the use of a number of available metal oxides has not yet been performed on a set containing multiple pharmaceutical substances.

\subsection{Preliminary Characterization of Metabolism Pathways}

In order to collect preliminary data on the course of the metabolism process and the structures of metabolites formed by the selected for comparison pharmaceutical substances, a detailed review of the available literature was performed [36,46,48-63].

Importantly, both HLM incubation and photocatalytic metabolism simulation experiments allowed the observation of numerous metabolic reactions, such as aliphatic and aromatic hydroxylation, oxidation, N-oxidation, S-oxidation, dealkylation, and dehydrogenation. Nevertheless, photocatalysis failed in case of several analyzed substances. For instance, photocatalytic transformation of toloxatone and orciprenaline did not give any of metabolites detected in HLM incubation. It should be noticed also that our previous study on photocatalytic metabolism simulation of toloxatone as a single substance allowed to obtain all metabolites formed in HLM experiment [36]. This inconsistency should be attributed to the presence of other analyzed substances in the mixture which may be responsible for inhibiting activity of applied photocatalysts. Noteworthy are cases of chlorprothixene, vardenafil, dapoxetine, and flunarizine where photocatalytic simulation experiments showed only partial efficiency in comparison to HLM experiment. Remarkable is also fact that one of trazodone metabolites was formed only in the photocatalytic metabolic simulation while absent in HLM experiment.

The summary of identified metabolism reactions is presented in Table 1. 
Table 1. Metabolites observed during HLM incubation and photocatalytic experiments.

\begin{tabular}{|c|c|c|c|c|c|c|c|c|c|c|c|c|c|c|c|}
\hline $\begin{array}{c}\text { Name } \\
\text { Structure }\end{array}$ & $\begin{array}{c}\mathrm{m} / \mathbf{z} \\
{[\mathrm{M}+\mathrm{H}]^{+}}\end{array}$ & $\begin{array}{c}\text { Metabolism } \\
\text { Reaction }\end{array}$ & HLM & $\mathrm{Bi}_{2} \mathrm{O}_{3}$ & $\mathrm{CeO}_{2}$ & $\mathrm{Co}_{3} \mathrm{O}_{4}$ & $\mathrm{Cu}_{2} \mathrm{O}$ & $\mathrm{SrTiO}_{3}$ & $\mathrm{TiO}_{2}$ & $\mathrm{TiO}_{2}$-CNTs & $\mathrm{TiO}_{2}-\mathrm{ZnO}$ & $\mathrm{WO}_{3}$ & $\mathrm{ZnFe}_{2} \mathrm{O}_{4}$ & $\mathrm{ZnO}$ & $\mathrm{ZrO}_{2}$ \\
\hline \multirow[t]{4}{*}{ Chlorprothixer } & 302.0764 & demethylation & + & + & + & + & + & + & + & + & + & + & + & + & + \\
\hline & 332.0870 & S-oxidation & + & + & + & + & + & + & + & + & + & + & + & + & + \\
\hline & 318.0714 & $\begin{array}{c}\text { demethylation } \\
\text { S-oxidation }\end{array}$ & + & - & - & - & - & - & + & - & + & + & - & - & - \\
\hline & 348.0819 & $\begin{array}{l}\text { S-oxidation } \\
\text { N-oxidation }\end{array}$ & + & - & - & - & - & - & - & - & - & - & - & - & - \\
\hline \multirow[t]{4}{*}{ Reboxetine } & 286.1437 & deethylation & + & - & + & - & - & + & + & + & + & + & - & + & + \\
\hline & 330.1699 & hydroxylation & + & - & - & - & - & - & - & - & - & + & - & - & - \\
\hline & 328.1543 & oxidation & + & - & - & - & - & - & + & - & + & + & - & - & - \\
\hline & 344.1492 & $\begin{array}{c}\text { hydroxylation } \\
\text { oxidation }\end{array}$ & + & + & + & + & + & + & + & + & + & + & + & + & + \\
\hline \multirow{4}{*}{ Trazodone } & & dealkylation & & & & & & & & & & & & & \\
\hline & $192.076 \%$ & oxidation & - & + & + & - & + & + & + & + & + & + & - & + & + \\
\hline & 388.1534 & hydroxylation & + & + & + & + & + & + & + & + & + & + & + & + & + \\
\hline & 406.1640 & dihydroxylation & + & + & + & + & + & + & + & + & + & + & + & + & + \\
\hline \multirow[t]{3}{*}{ Quetiapine } & 340.1478 & dealkylation & + & + & + & - & + & - & + & + & + & + & + & + & + \\
\hline & 296.1215 & dealkylation & + & + & + & + & + & + & + & + & + & + & + & + & + \\
\hline & 400.1689 & hydroxylation & + & + & + & + & + & + & + & + & + & + & + & + & + \\
\hline
\end{tabular}


Table 1. Cont.

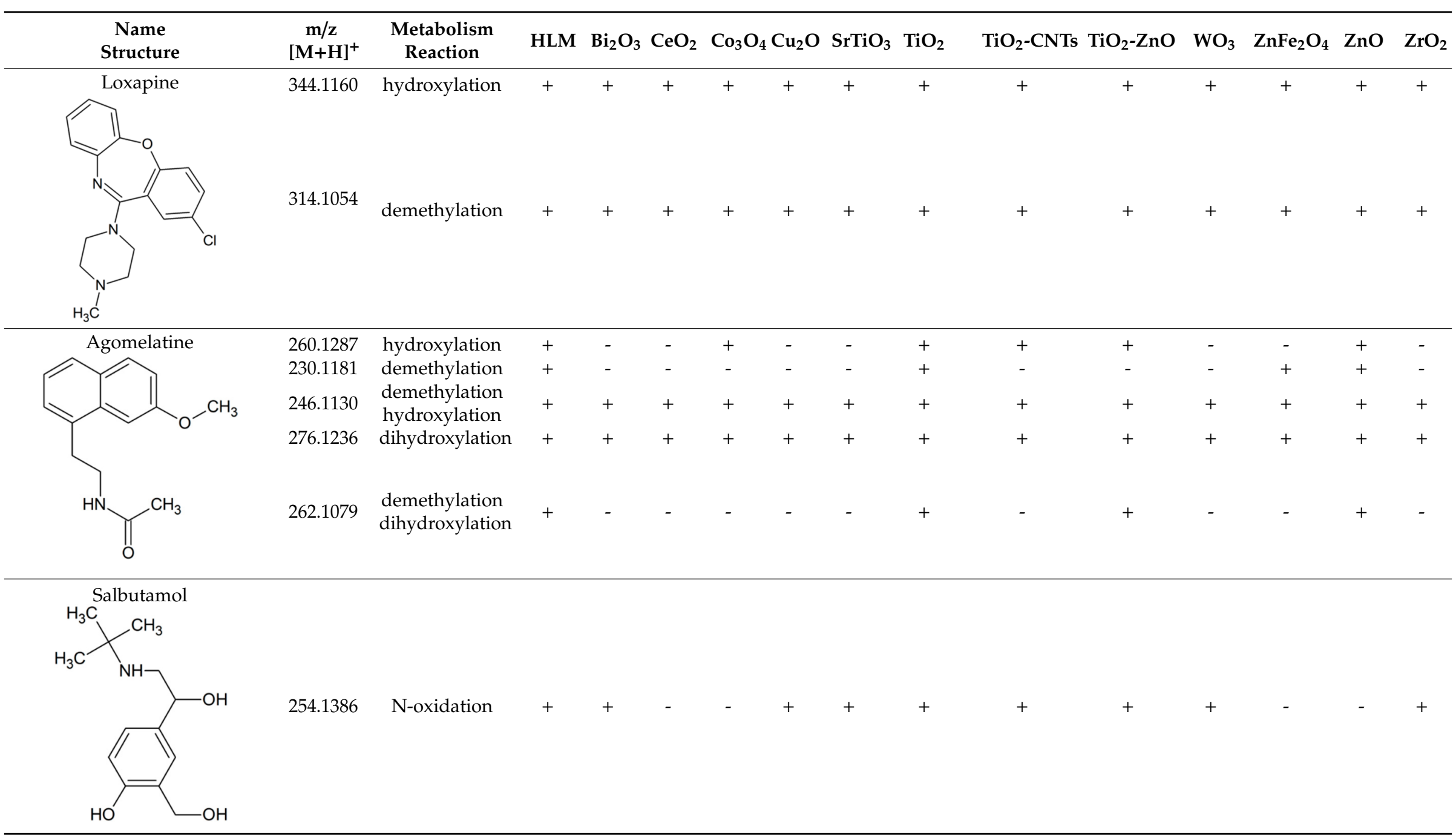


Table 1. Cont.

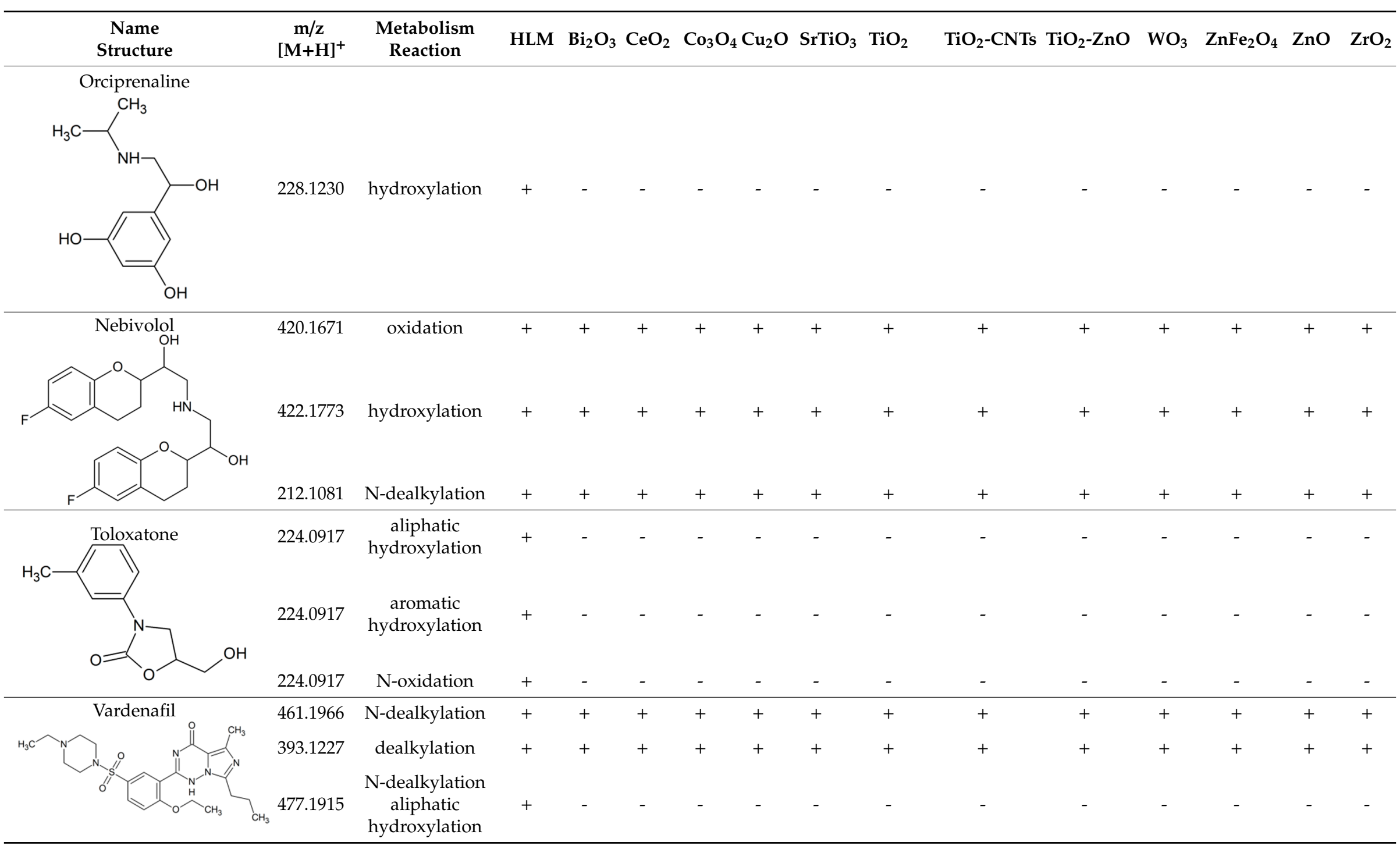


Table 1. Cont.

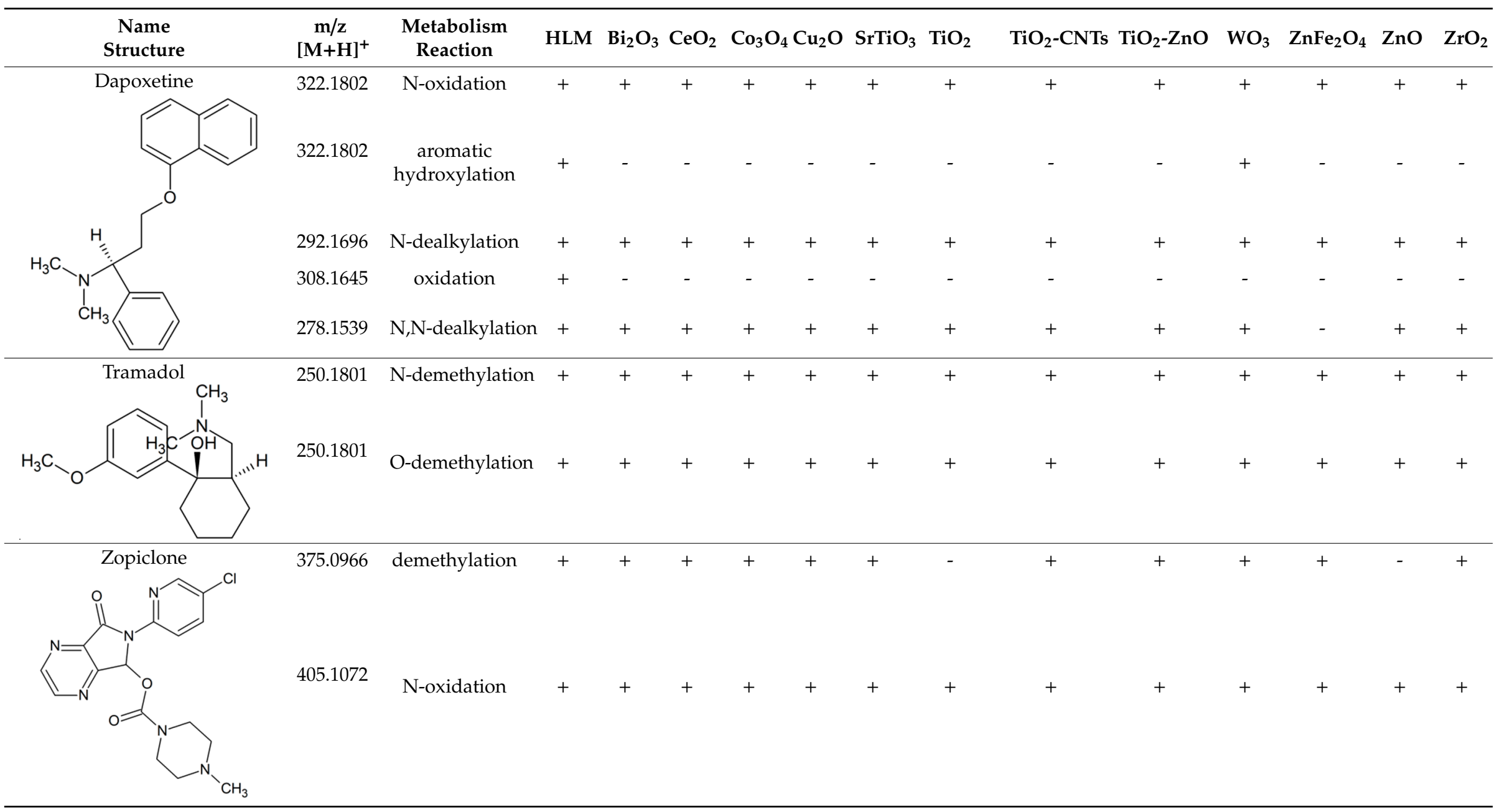


Table 1. Cont.

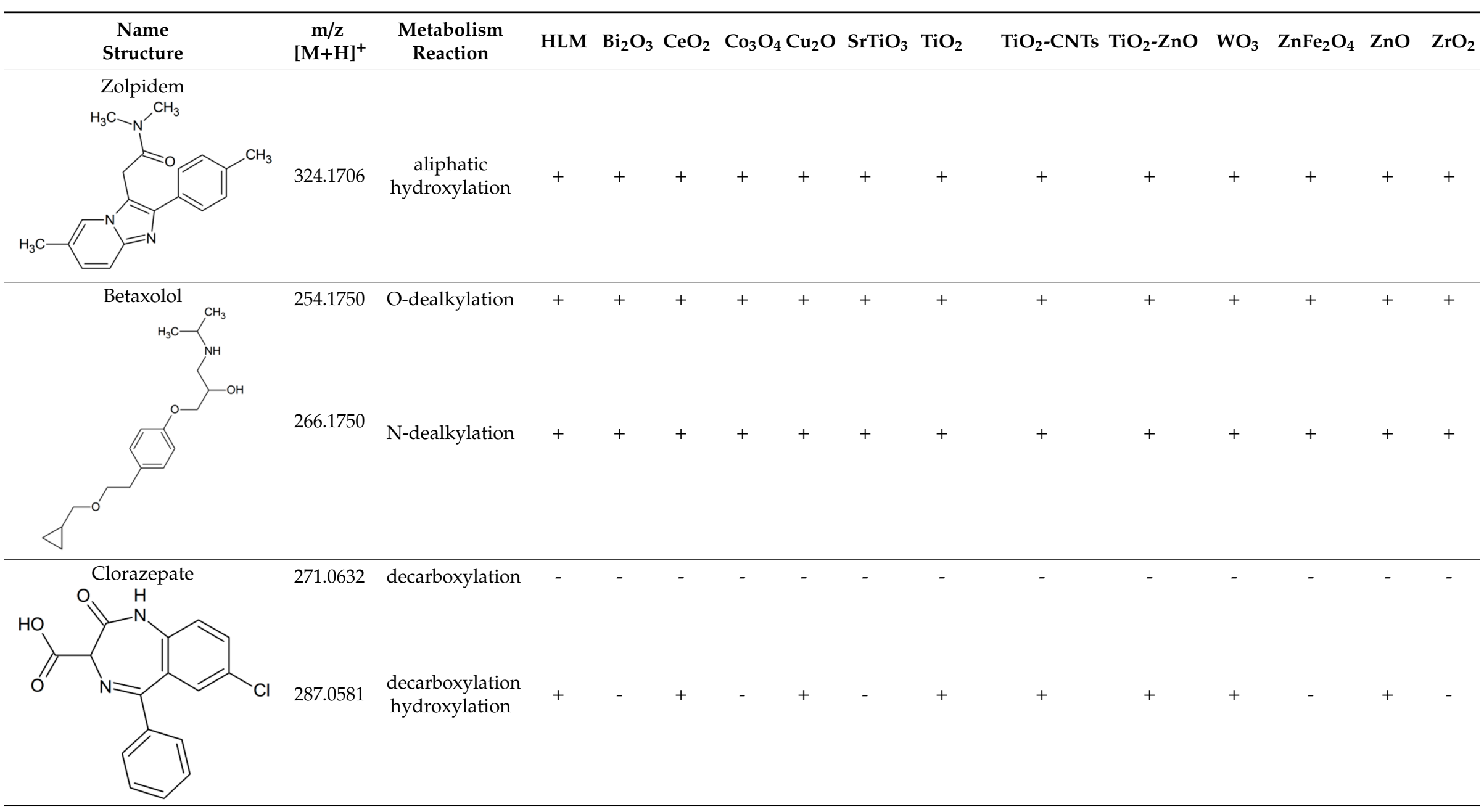


Table 1. Cont

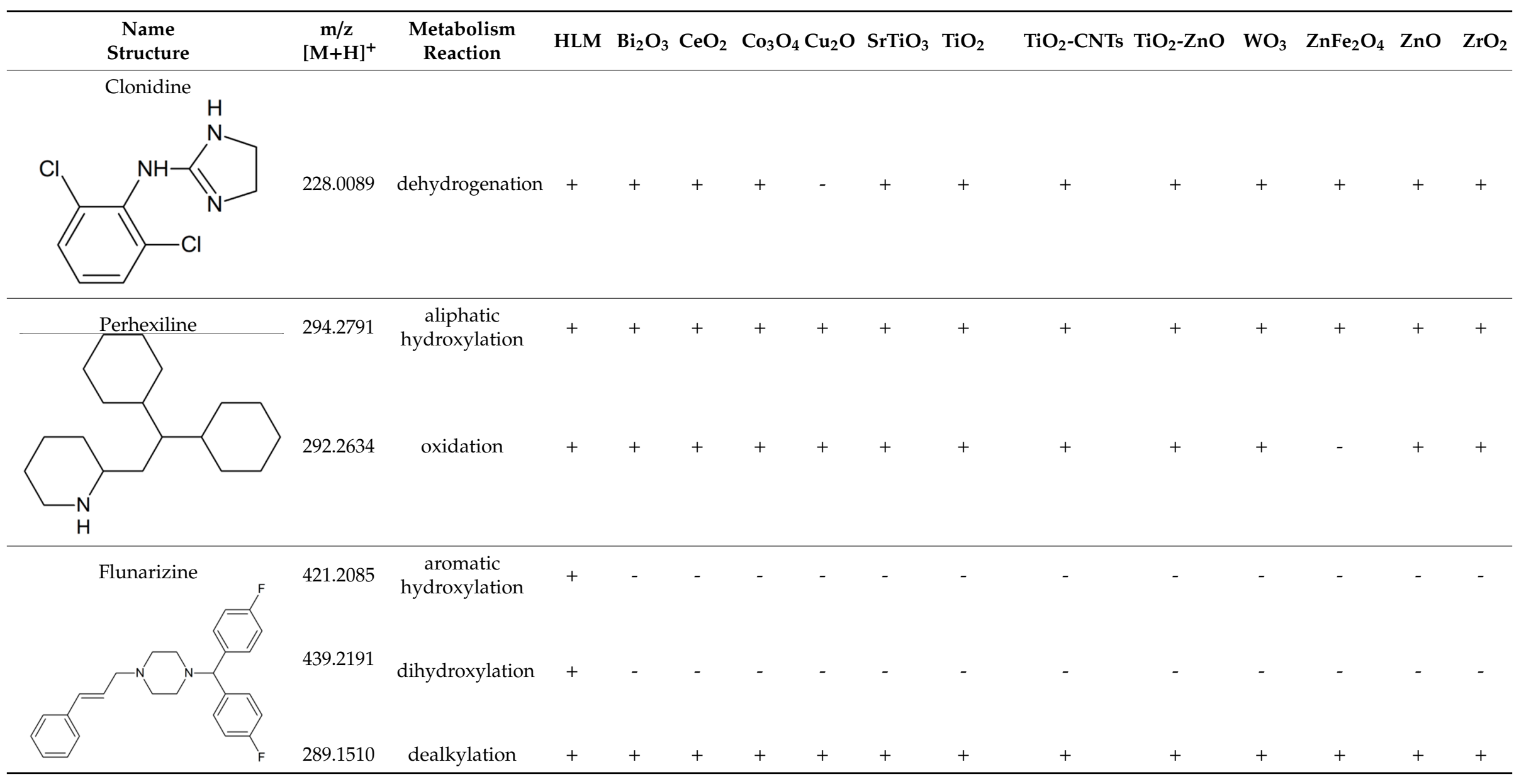




\subsection{Chemometric Analysis}

The multivariate chemometric data analysis, incorporating principal component analysis (PCA) and hierarchical cluster analysis (HCA), was performed in order to compare the suitability of chosen photocatalysts in further drug metabolism research.

\subsubsection{PCA}

The PCA is a commonly applied method used for data exploration and visualization of the relationships between samples. Its principle relies on conversion of the original variables to the equal number of latent variables (principal components, PCs), which are uncorrelated, and explain the largest percentage of the data variability.

One of the most important arguments for the use of PCA is its ability to reduction of the data dimensionality. In this research dimensionality of the dataset is 961 (entities corresponding to their $\mathrm{m} / \mathrm{z}$ detected by the MS). Because of the correlations existing between the variables, PCA enabled the significant decrease of the dimensionality. It allowed straightforward presentation of data using 2-dimensional plot.

All obtained profiles (shown in Supplementary Figures S1-S15) recorded in time-of-flight (TOF) operation mode and treated using Mass Profiler Professional software giving 961 entities. After filtration and moderated $\mathrm{t}$-Test ( $\mathrm{p} \leq 0.05, \mathrm{FC} \geq 7$ ), 51 entities were obtained. The 2-D PCA allowed to explain $60.17 \%$ of the data variance (Figure 1 - squares of each color stands for one experiment). As can be seen, Control was placed close to the standard sample (working solution of model mixture before experiments) which testifies no occurrence of metabolic reactions. HLM samples were placed on the opposite side of PCA plot. All samples representing photocatalytic experiments were grouped between HLM and control, which confirms the presence of the analyzed drugs metabolites. First of all, it should be noticed that $\mathrm{WO}_{3}$ catalyzed samples were located in the nearest distance to HLM samples. On the contrary to the remaining photocatalytic samples, $\mathrm{WO}_{3}$ group was not shifted along the $y$-axis which clearly suggest that majority of transformation products correspond to metabolites formed during HLM incubation. The remaining photocatalytic experiments can be divided into four groups. The first of these experiments consisted of $\mathrm{TiO}_{2} / \mathrm{ZnO}$ and $\mathrm{ZnO}$ placed relatively close to HLM samples in comparison to other photocatalytic samples. The second group containing $\mathrm{TiO}_{2}$ and $\mathrm{SrTiO}_{3}$ was located in the middle of $x$-axis of the PCA plot, which indicate moderate metabolism mimicking efficiency. On the other hand, the group consisting of $\mathrm{ZnFe}_{2} \mathrm{O}_{4}$ and $\mathrm{Cu}_{2} \mathrm{O}$ was placed the most closely to control, which attests to their low suitability in drug metabolism simulation studies. The last cluster grouping $\mathrm{Bi}_{2} \mathrm{O}_{3}, \mathrm{CeO}_{2}, \mathrm{Co}_{3} \mathrm{O}_{4}, \mathrm{ZrO}_{2}$ and $\mathrm{TiO}_{2}-\mathrm{CNT}$ showed rather poor activity in the context of drugs metabolites formation. It should be also noticed that they were shifted to the greatest extent along the $y$-axis which suggest that significant amount of formed transformation products cannot be considered as the drugs metabolites. In order to present more detailed relationships between experiments, HCA analysis was additionally performed. 


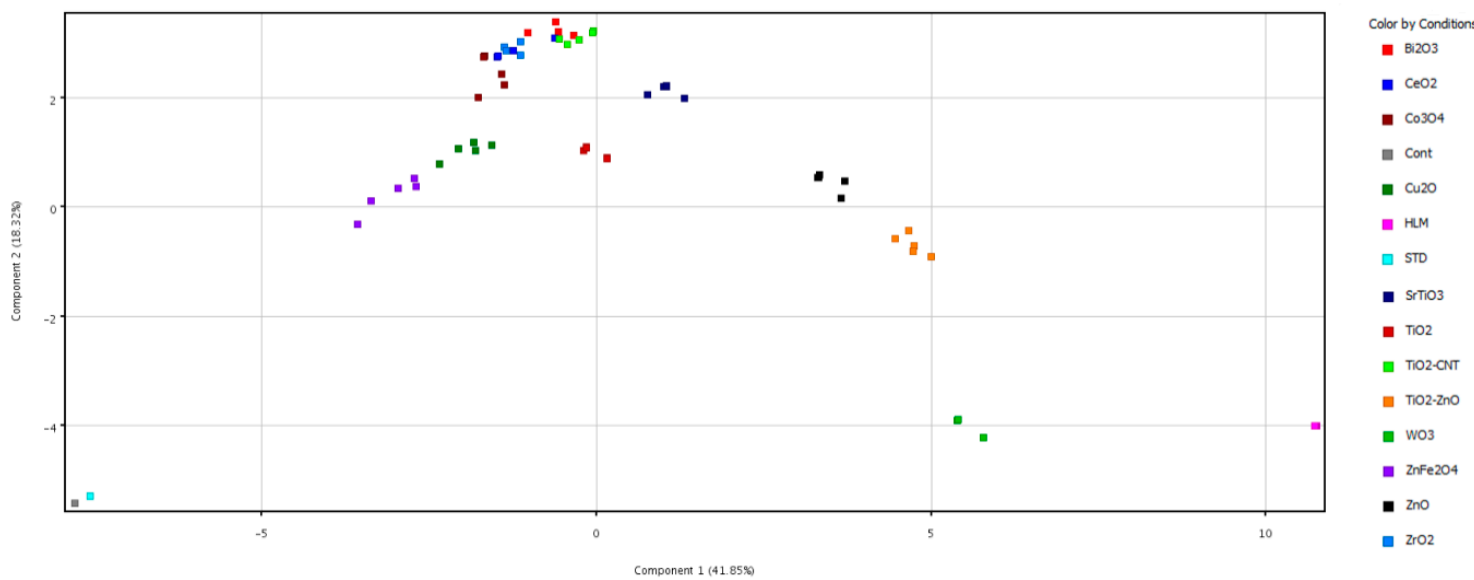

Figure 1. 2D PCA plot of the standard sample (STD), Control (Cont), HLM after 120 min of incubation and photocatalytic experiments samples after $60 \mathrm{~min}$ of irradiation.

\subsubsection{Hierarchical Cluster Analysis and Heatmap}

Hierarchical cluster analysis is one more chemometric technique which can be used to determine the relationships between the studied samples. In general, the clustering methods depend on identification of similarities between the samples which can be represented by the distance between them. It should be noticed that the similarity between samples increases in parallel with decreasing distance between them. The results of clustering could be graphically presented on the dendrogram (Euclidean distance metrics and Ward's method clustering algorithm were used in this study).

As was shown in Figure 2, HCA gave similar results to $\mathrm{PCA}-\mathrm{WO}_{3}$ samples presented the highest resemblance to HLM experiment. In general, all experiments were split into two main clusters. The first group consisted of aforementioned $\mathrm{WO}_{3}-\mathrm{HLM}$ and $\mathrm{TiO}_{2} / \mathrm{ZnO}-\mathrm{ZnO}$ pairs. The second main cluster grouped samples corresponding to the remaining experiments. Within this group, Standard - Control pair was the most outlying. Similarly to $\mathrm{PCA}, \mathrm{Bi}_{2} \mathrm{O}_{3}, \mathrm{CeO}_{2}, \mathrm{Co}_{3} \mathrm{O}_{4}, \mathrm{ZrO}_{2}$ and $\mathrm{TiO}_{2}-\mathrm{CNT}$ experiments were grouped together. Additionally, HCA showed that this cluster remained the most distant from Standard - Control pair. On the contrary to the PCA, $\mathrm{ZnFe}_{2} \mathrm{O}_{4}$ and $\mathrm{SrTiO}_{3}$ samples were grouped together with $\mathrm{Bi}_{2} \mathrm{O}_{3}, \mathrm{CeO}_{2}, \mathrm{Co}_{3} \mathrm{O}_{4}, \mathrm{ZrO}_{2}$ and $\mathrm{TiO}_{2}-\mathrm{CNT}$ cluster. Additionally, $\mathrm{Cu}_{2} \mathrm{O}$ and $\mathrm{TiO}_{2}$ were classified as a pair.
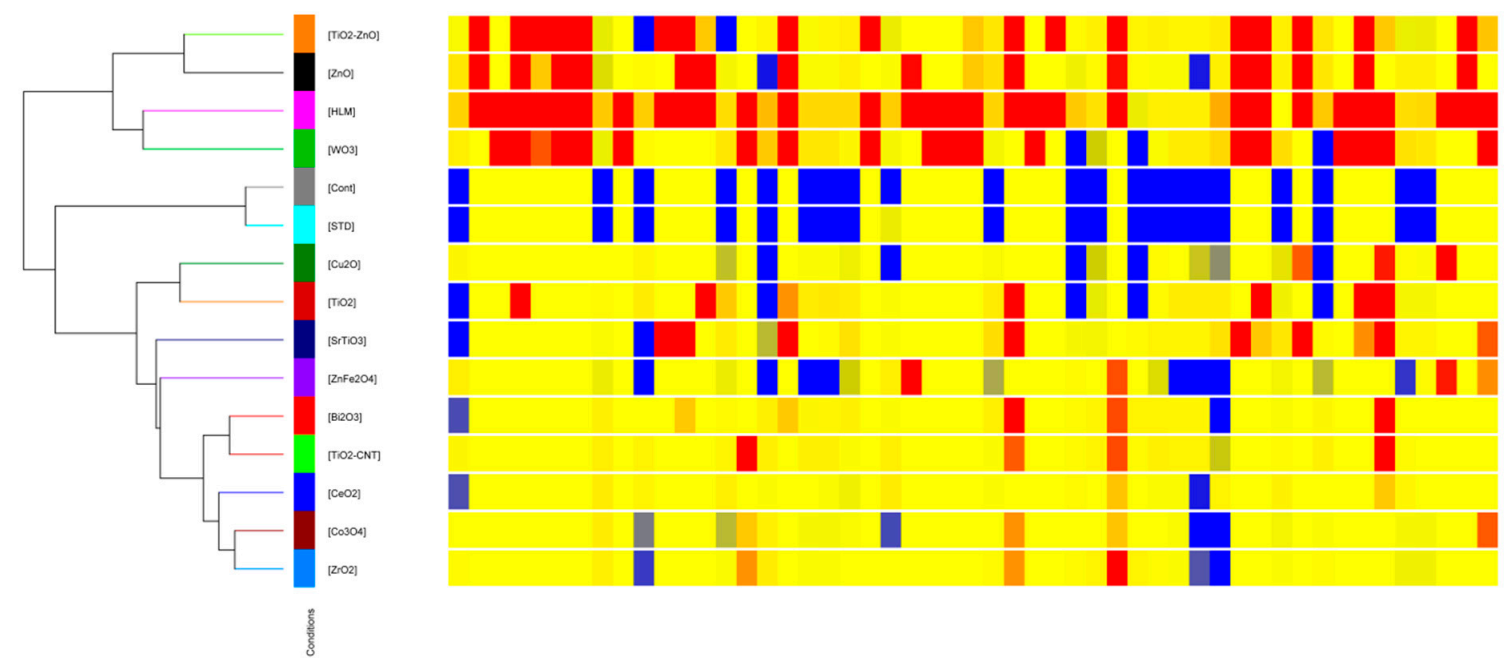

Figure 2. Cluster dendrogram and heatmap of the standard sample (STD), Control (Cont), HLM after $120 \mathrm{~min}$ of incubation and photocatalytic experiments samples after $60 \mathrm{~min}$ of irradiation. 
The relationships between abundances of molecular entities used for HCA construction were shown as a heatmap (Figure 2). Stripes on the map represent molecular entities (blue color: low abundance, red: high, yellow: average abundance). The heatmap clearly shows the cause of conducted experiments splitting into two clusters in HCA. The first cluster contained a high concentration of entities corresponding to metabolites which is reflected by numerous red strips. In this context, $\mathrm{WO}_{3}$ samples exhibit the highest resemblance to HLM. The second cluster contained a moderate or low concentration of entities corresponding to metabolites (yellow and blue strips). Unsuspectingly, the highest number of blue strips were present in standard and control. A low concentration of metabolites was observed in the case of $\mathrm{ZnFe}_{2} \mathrm{O}_{4}$ and $\mathrm{Cu}_{2} \mathrm{O}$ experiments in particular.

\section{Experimental}

\subsection{Chemicals and Reagents}

Chlorprothixene hydrochloride, quetiapine hemifumarate, loxapine succinate, toloxatone, vardenafil hydrochloride trihydrate, dapoxetine hydrochloride, salbutamol hemisulfate, orciprenaline hemisulfate, betaxolol hydrochloride, clonidine hydrochloride, perhexiline maleate, and flunarizine dihydrochloride were purchased from Sigma Aldrich Co. (St. Louis, MO, USA). Imovane $7.5 \mathrm{mg}$ tablets (Sanof-Aventis, Gentilly, France)—zopiclon, Stilnox 10mg tablets (Sanofi-Aventis, Tours France)-zolpidem tartrate, Nebilet 5mg tablets (Berlin-Chemie Menarini, Glienicker Weg, Germany)—nebivolol hydrochloride, Trittico CR 75 mg tablets (Aziende Chimiche Riunite Angelini Francesco, Rome, Italy) — trazodone hydrochloride, Tranxene $5 \mathrm{mg}$ capsules (Sanofi-Aventis, Paris, France)-clorazepate dipotassium, Edronax $4 \mathrm{mg}$ tablets (Pfizer Europe, Sandwich Kent, Great Britain)—reboxetine methanesulfonate, Valdoxan $25 \mathrm{mg}$ tablets (Les Laboratoires Servier, Suresnes, France)—agomelatine, Poltram 50 solution for injection (Polpharma, Starogard Gdański, Poland) - tramadol hydrochloride were obtained in the local pharmacy.

Water (LC-MS Ultra grade), $\beta$-nicotinamide adenine dinucleotide 2 -phosphate reduced tetrasodium salt hydrate (NADPH), human liver microsomes (HLM), sodium phosphate monobasic monohydrate salt, sodium phosphate dibasic anhydrous salt, $\mathrm{TiO}_{2}$ (Aeroxide $囚 25$ ), nanopowder $21 \mathrm{~nm}$ particle size (BET), $50 \mathrm{~m}^{2} / \mathrm{g}$ specific surface area (SSA), $\mathrm{ZnO}$, nanopowder $<100 \mathrm{~nm}$ particle size, $10-25 \mathrm{~m}^{2} / \mathrm{g}$ SSA and $\mathrm{WO}_{3}$, nanopowder $<100 \mathrm{~nm}$ particle size (TEM), $8.3 \mathrm{~m}^{2} / \mathrm{g}$ SSA were obtained from Sigma-Aldrich (St. Louis, MO, USA). $\mathrm{Bi}_{2} \mathrm{O}_{3}$, nanopowder $80 \mathrm{~nm}$ particle size (TEM), $25 \mathrm{~m}^{2} / \mathrm{g}$ SSA, 99.9\%, (Figure S16), $\mathrm{CeO}_{2}$, nanopowder 10-30nm particle size (TEM), 30-50 m²/g SSA, 99.97\%, (Figure S17), $\mathrm{Co}_{3} \mathrm{O}_{4}$, nanopowder 10-30 nm particle size (TEM), 50-150 m²/g SSA, 99\% (Supplementary Figure $\mathrm{S} 18$ ), $\mathrm{Cu}_{2} \mathrm{O}$, nanopowder $18 \mathrm{~nm}$ particle size (SEM), $52.46 \mathrm{~m}^{2} / \mathrm{g}$ SSA, $99.86 \%$ (Supplementary Figure $\mathrm{S} 19$ ), $\mathrm{SrTiO}_{3}$, nanopowder, $100 \mathrm{~nm}$ particle size (cubic phase, TEM), $11.02 \mathrm{~m}^{2} / \mathrm{g} \mathrm{SSA}, 99.9 \%$, (Supplementary Figure S20), carbon nanotube- $\mathrm{TiO}_{2}$ consisting of $\mathrm{CNTs} 20 \mathrm{wt} \%$ : $\mathrm{TiO}_{2}$-rutile $80 \mathrm{wt} \%$ CNTs (outside diameter: $>50 \mathrm{~nm}$, inside diameter: 5-15nm, length: 5-20um), $\mathrm{TiO}_{2}$ (rutile, 100 300nm, spherical, SEM), $18.5 \mathrm{~m}^{2} / \mathrm{g} \mathrm{SSA}$, (Figure S21), UV shielding nanopowder, $50 \mathrm{~nm}$ particle size consisting of $\mathrm{ZnO} / 49 \mathrm{wt} \%+\mathrm{TiO}_{2} / 49 \mathrm{wt} \%$ (TEM), 25-50 m²/g SSA, (Figure S22), $\mathrm{ZnFe}_{2} \mathrm{O}_{4}$, nanopowder 10-30 nm particle size (TEM), 98.5\%, (Figure S23), $\mathrm{ZrO}_{2}$, nanopowder $40 \mathrm{~nm}$ particle size (TEM), $20-40 \mathrm{~m}^{2} / \mathrm{g}$ SSA, 99\%, (Figure S24) were purchased from US Research Nanomaterials, Inc. (Houston, TX, USA). Acetonitrile (hypergrade for LC-MS) was purchased from Merck (Darmstadt, Germany) and 98\% formic acid (mass spectroscopy grade) was obtained from Fluka (Taufkirchen, Germany).

\subsection{Sample Preparation}

Stock solutions of drug standards freely soluble in water (chlorprothixene hydrochloride, quetiapine hemifumarate, loxapine succinate, dapoxetine hydrochloride, salbutamol hemisulfate, orciprenaline hemisulfate, betaxolol hydrochloride, clonidine hydrochloride, flunarizine dihydrochloride) were prepared in water $\left(1 \mathrm{mg} \mathrm{mL}^{-1}\right)$. 
Stock solutions of toloxatone and vardenafil hydrochloride trihydrate were made in water (2 $\left.\mathrm{mg} \mathrm{mL}^{-1}\right)$.

Stock solution of perhexiline maleate was made in the mixture consisting of $10 \%$ acetonitrile and $90 \%$ water $\left(1 \mathrm{mg} \mathrm{mL}^{-1}\right)$.

Stock solution of tramadol hydrochloride was prepared by diluting pharmaceutical formulation with water to obtain solution $\left(10 \mathrm{mg} \mathrm{mL}^{-1}\right)$.

The substances obtained from tablets and capsules in the equivalents of $10 \mathrm{mg}$ (zolpidem tartrate, reboxetine methanesulfonate, trazodone hydrochloride, quetiapine hemifumarate, nebivolol hydrochloride, clorazepate dipotassium) or $100 \mathrm{mg}$ (agomelatine, zopiclone) of pharmaceuticals were weighted and swept for $5 \mathrm{~min}$ with $10 \mathrm{~mL}$ of water or acetonitrile. Semi-stock solution was obtained by mixing appropriate volumes of stock solutions and diluting with water to obtain $150 \mu \mathrm{M}$ concentrations of each substance.

The working solutions were prepared by diluting semi-stock solution with gradient grade water, to obtain $7.5 \mu \mathrm{M}$ concentration of each pharmaceutical substance in the case of photocatalytic experiments and $15 \mu \mathrm{M}$ in the case of HLM incubation.

\subsection{Photocatalytic Simulation of Metabolism}

The photocatalytic simulation of metabolism was performed at concentration $7.5 \mu \mathrm{M}$ of tested drugs. The applied catalysts loadings were set to $100 \mathrm{mg} \mathrm{L}^{-1}$. For all experiments, suspensions were transferred into $3.5 \mathrm{~mL}$ quartz caped cells $(1=1 \mathrm{~cm})$ and stirred at $500 \mathrm{rpm}$ (microstirrer Cimarel: Telemodul, Thermo Electron LED GmbH, Germany) in the dark for 30 min to achieve adsorption-desorption equilibrium. Next, reaction cells were mounted horizontally in Atlas Suntest CPS+ photostability chamber with D65 filter (Linsengericht, Germany), and irradiated simultaneously with stirring. The irradiance was set to $750 \mathrm{~W} \mathrm{~m}^{-2}$ which corresponds to energy dose of $2700 \mathrm{~kJ} \mathrm{~m}^{-2}$ $\mathrm{h}^{-1}$. The temperature in the chamber was controlled and kept below $35^{\circ} \mathrm{C}$. Aliquots $(100 \mu \mathrm{L})$ were collected after $60 \mathrm{~min}$ of irradiation. After centrifuging at 13,500 rpm for 5 minutes, $50 \mu \mathrm{L}$ of samples were subjected to UHPLC-ESI-Q-TOF analysis.

\subsection{HLM Metabolism Simulation}

The phase I transformation process was conducted using microsomes fraction. Total volume of reaction suspension was $200 \mu \mathrm{L}$ including $0.5 \mathrm{mg} \mathrm{mL}^{-1}$ microsomes, $50 \mathrm{mM}$ phosphate buffer ( $\mathrm{pH} 7.4$ ) and $15 \mu \mathrm{M}$ substrate. The reaction mixture was pre-incubated at $37^{\circ} \mathrm{C}$ for $2 \mathrm{~min}$ and then the metabolic reactions were initiated by addition of $10 \mu \mathrm{L}$ NADPH $(50 \mathrm{mM})$. The reaction was terminated after $120 \mathrm{~min}$ of incubation with $200 \mu \mathrm{L}$ of ice-cold acetonitrile-methanol mixture (1:1). The final concentration of each studied pharmaceutical was equal to $7.5 \mu \mathrm{M}$. Next, the precipitated samples were centrifuged at $13,500 \mathrm{rpm}$ for 10 minutes at $4{ }^{\circ} \mathrm{C}$ and the supernatants $(50 \mu \mathrm{L})$ were transferred into autosampler vials for LC-MS analysis. The negative control samples (Control) were prepared as described above without addition of NADPH solution.

\subsection{LC-MS Analysis}

The LC-MS analysis was performed with the use of Agilent Accurate-Mass Q-TOF LC/MS G6520B system with dual electrospray (DESI) ionization source and Infinity 1290 ultra-high-pressure liquid chromatography system consisting of: binary pump G4220A, FC/ALS thermostat G1330B, autosampler G4226A, DAD detector G4212A, TCC G1316C module (Agilent Technologies, Santa Clara, CA, USA) and Kinetex C18 $(2.1 \times 50 \mathrm{~mm}, \mathrm{dp}=1.7 \mu \mathrm{m})$ column with C18 precolumn guard (Phenomenex, Torrance, CA, USA). A mixture of ultrapure water with addition of $0.1 \%$ solution of formic acid (A) and acetonitrile (B) was used as a mobile phase. The gradient elution was carried out at constant flow $0.3 \mathrm{~mL} \mathrm{~min}^{-1}$ from $95 \% \mathrm{~A}(5 \% \mathrm{~B})$ to $70 \% \mathrm{~A}(30 \% \mathrm{~B})$ 0-7.50 min and then $55 \% \mathrm{~A}(45 \% \mathrm{~B})$ to $5 \% \mathrm{~A}(95 \%$ B) 7.50-12.50 min for all analysis. One-and-a-half-minute equilibrium time was performed to return to initial conditions. The injection volume was $4 \mu \mathrm{l}$ and the column temperature was maintained at 
$35{ }^{\circ} \mathrm{C}$. MassHunter workstation software in version B.08.00 was used for the control of the system, data acquisition, qualitative and quantitative analysis.

The optimization of the instrument conditions started from the proper tuning of Q-TOF detector in a positive mode with the use of Agilent ESI-L tuning mix in the extended dynamic range $(2 \mathrm{GHz})$. The following instrument settings were applied: gas temperature: $325^{\circ} \mathrm{C}$, drying gas: $10 \mathrm{~L} / \mathrm{min}$, nebulizer pressure: $40 \mathrm{psig}$, capillary voltage: $3000 \mathrm{~V}$, fragmentor voltage: $175 \mathrm{~V}$, skimmer voltage: $65 \mathrm{~V}$, octopole $1 \mathrm{RF}$ voltage: $750 \mathrm{~V}$.

Data acquisition was performed in centroids with the use of TOF (MS) and auto MS/MS mode. The spectral parameters for both modes were: mass range: $80-950 \mathrm{~m} / \mathrm{z}$ and the acquisition rate: $1.5 \mathrm{spectra} / \mathrm{s}$. To ensure accuracy in masses measurements, a reference mass correction was used and masses 121.050873 and 922.009798 were used as lock masses.

\subsection{Chemometric Analysis}

Fourteen metabolism experiments: HLM (after 120 min of incubation), Control sample (HLM without NADPH), twelve photocatalytic experiments (each after $60 \mathrm{~min}$ of exposition) were made in five replications for each one experiment. Additionally, standard sample (working solution before experiments) was added in chemometric analysis also. In this manner a set of seventy-five samples for fifteen different experiments was obtained. For all samples, high resolution liquid chromatography-mass spectrometry analysis was performed in TOF mode and their profiles were recorded. Data background ion noise cleaning and extraction of the list of the ions characteristic for metabolite profiles of analyzed substances were made by molecular feature extraction (MFE) algorithm provided by Mass Hunter Qualitative Analysis software version B.06.00 (Agilent). The following settings of MFE parameters were chosen as: isotope model: common organic molecules with peak spacing tolerance $0.0025 \mathrm{~m} / \mathrm{z}$, more than 2000 counts for the compound filter and single charge state of the analyzed ions. In order to perform PCA and HCA, MPP software in version 12.61 (Agilent and Strand Life Sciences Pvt. Ltd.) was used.

\section{Conclusions}

The aim of the study was to compare the performance of a set of twelve metal oxides in the context of their use in the simulation of drug metabolism. For this purpose, a mixed solution of twenty model pharmaceutical substances was used. Separate photocatalytic experiments and incubation with human liver microsomes as a reference method were performed. The samples were subjected to UHPLC-ESI-Q-TOF MS analysis and the obtained metabolic profiles were compared using advanced chemometric methods due to the multidimensionality of data. Graphical presentation of the study results in the form of a PCA plot and cluster dendrogram allowed for their interpretation.

All the used photocatalysts confirmed their effectiveness, while the exact outcome of the study indicates a clear advantage of $\mathrm{WO}_{3}$-assisted photocatalysis over other metal oxides experiments used in this comparison. $\mathrm{WO}_{3}$-assisted photocatalytic experiment showed the best fit in terms of quantity and quality to the metabolic profile obtained from HLM incubation. On this basis, $\mathrm{ZnFe}_{2} \mathrm{O}_{4}$ and $\mathrm{Cu}_{2} \mathrm{O}$ showed the lowest efficiency in relation to the key test assumptions. However, satisfactory results have also been achieved with the use of zinc oxide. Moderate metabolism mimicking efficiency in the case of $\mathrm{TiO}_{2}$ experiment is somewhat surprising. On the other hand, despite the rather poor result of a single photocatalyst in this case, its coupling with the zinc oxide is also relevant as it significantly improves the efficiency of both, and this combination clearly gains its usefulness in the context of drug metabolism studies.

For this reason, it seems promising to study various combinations of metal oxides, e.g., zinc oxide and tungsten oxide, or other combinations of zinc oxide and titanium dioxide to further the development of photocatalytic methods of the drug metabolism simulation.

Supplementary Materials: The following are available online at http://www.mdpi.com/2073-4344/10/1/26/s1, Figure S1: Overlay of the total ion current (TIC) from $\mathrm{Bi}_{2} \mathrm{O}_{3}$ photocatalytic experiment, Figure S2: Overlay of the 
total ion current (TIC) from $\mathrm{CeO}_{2}$ photocatalytic experiment, Figure S3: Overlay of the total ion current (TIC) from $\mathrm{Co}_{3} \mathrm{O}_{4}$ photocatalytic experiment, Figure S4: Overlay of the total ion current (TIC) from $\mathrm{Cu}_{2} \mathrm{O}$ photocatalytic experiment, Figure S5: Overlay of the total ion current (TIC) from $\mathrm{SrTiO}_{3}$ photocatalytic experiment, Figure S6: Overlay of the total ion current (TIC) from $\mathrm{TiO}_{2}$ photocatalytic experiment, Figure S7: Overlay of the total ion current (TIC) from $\mathrm{TiO}_{2}-$ CNTs photocatalytic experiment, Figure S8: Overlay of the total ion current (TIC) from $\mathrm{TiO}_{2}-\mathrm{ZnO}$ photocatalytic experiment, Figure S9: Overlay of the total ion current (TIC) from $\mathrm{WO}_{3}$ photocatalytic experiment, Figure S10: Overlay of the total ion current (TIC) from $\mathrm{ZnFe}_{2} \mathrm{O}_{4}$ photocatalytic experiment, Figure S11: Overlay of the total ion current (TIC) from $\mathrm{ZnO}$ photocatalytic experiment, Figure S12: Overlay of the total ion current (TIC) from $\mathrm{ZrO}_{2}$ photocatalytic experiment, Figure S13: Overlay of the total ion current (TIC) from HLM incubation, Figure S14: Overlay of the total ion current (TIC) from HLM control sample, Figure S15: Overlay of the total ion current (TIC) from standard sample, Figure S16: TEM image of $\mathrm{Bi}_{2} \mathrm{O}_{3}$, Figure S17: TEM image of $\mathrm{CeO}_{2}$, Figure S18: TEM image of $\mathrm{Co}_{3} \mathrm{O}_{4}$, Figure S19: SEM image of $\mathrm{Cu}_{2} \mathrm{O}$, Figure S20: TEM image of $\mathrm{SrTiO}_{3}$, Figure S21: SEM image of $\mathrm{TiO}_{2}-\mathrm{CNTs}$, Figure S22: TEM image of $\mathrm{TiO}_{2}-\mathrm{ZnO}$, Figure S23: TEM image of $\mathrm{ZnFe}_{2} \mathrm{O}_{4}$, Figure S24: TEM image of $\mathrm{ZrO}_{2}$.

Author Contributions: Conceptualization, R.S.; data curation, R.S.; formal analysis, M.G. and J.T.; investigation, M.G., J.T. and R.S.; methodology, R.S.; supervision, R.S.; writing-original draft preparation, M.G., J.T. and R.S. All authors have read and agreed to the published version of the manuscript.

Funding: This research received no external funding.

Conflicts of Interest: The authors declare no conflict of interest.

\section{References}

1. Mills, A.; Le Hunt, S. An overview of semiconductor photocatalysis. J. Photochem. Photobiol. Chem. 1997, 108, 1-35. [CrossRef]

2. Fujishima, A.; Honda, K. Electrochemical Photolysis of Water at a Semiconductor Electrode. Nature 1972, 238, 37. [CrossRef]

3. Ibhadon, A.; Fitzpatrick, P. Heterogeneous Photocatalysis: Recent Advances and Applications. Catalysts 2013, 3, 189-218. [CrossRef]

4. Nakata, K.; Fujishima, A. $\mathrm{TiO}_{2}$ photocatalysis: Design and applications. J. Photochem. Photobiol. C Photochem. Rev. 2012, 13, 169-189. [CrossRef]

5. Herrmann, J.-M. Heterogeneous photocatalysis: Fundamentals and applications to the removal of various types of aqueous pollutants. Catal. Today 1999, 53, 115-129. [CrossRef]

6. Hashimoto, K.; Irie, H.; Fujishima, A. $\mathrm{TiO}_{2}$ Photocatalysis: A Historical Overview and Future Prospects. Jpn. Appl. Phys. 2005, 44, 8269. [CrossRef]

7. Konstantinou, I.K.; Albanis, T.A. Photocatalytic transformation of pesticides in aqueous titanium dioxide suspensions using artificial and solar light: Intermediates and degradation pathways. Appl. Catal. B Environ. 2003, 42, 319-335. [CrossRef]

8. Ochiai, T.; Fujishima, A. Photoelectrochemical properties of $\mathrm{TiO}_{2}$ photocatalyst and its applications for environmental purification. J. Photochem. Photobiol. C Photochem. Rev. 2012, 13, 247-262. [CrossRef]

9. Cunha, D.L.; Kuznetsov, A.; Achete, C.A.; da Hora Machado, A.E.; Marques, M. Immobilized $\mathrm{TiO}_{2}$ on glass spheres applied to heterogeneous photocatalysis: Photoactivity, leaching and regeneration process. PeerJ 2018, 6, e4464. [CrossRef]

10. Malato, S.; Blanco, J.; Cáceres, J.; Fernández-Alba, A.R.; Agüera, A.; Rodrıguez, A. Photocatalytic treatment of water-soluble pesticides by photo-Fenton and $\mathrm{TiO}_{2}$ using solar energy. Catal. Today 2002, 76, $209-220$. [CrossRef]

11. Lazar, M.A.; Varghese, S.; Nair, S.S. Photocatalytic Water Treatment by Titanium Dioxide: Recent Updates. Catalysts 2012, 2, 572-601. [CrossRef]

12. Matsunaga, T.; Tomoda, R.; Nakajima, T.; Wake, H. Photoelectrochemical sterilization of microbial cells by semiconductor powders. FEMS Microbiol. Lett. 1985, 29, 211-214. [CrossRef]

13. Kayano, S.; Yoshihiko, K.; Kazuhito, H.; Akira, F. Bactericidal and Detoxification Effects of $\mathrm{TiO}_{2} \mathrm{Thin}_{\mathrm{Film}}$ Photocatalysts. Environ. Sci. Technol. 1998, 32, 726-728. [CrossRef]

14. Ohko, Y.; Utsumi, Y.; Niwa, C.; Tatsuma, T.; Kobayakawa, K.; Satoh, Y.; Kubota, Y.; Fujishima, A. Self-sterilizing and self-cleaning of silicone catheters coated with $\mathrm{TiO}_{2}$ photocatalyst thin films: A preclinical work. J. Biomed. Mater. Res. 2001, 58, 97-101. [CrossRef] 
15. Yu, J.C.; Ho, W.; Lin, J.; Yip, H.; Wong, P.K. Photocatalytic Activity, Antibacterial Effect, and Photoinduced Hydrophilicity of $\mathrm{TiO}_{2}$ Films Coated on a Stainless Steel Substrate. Environ. Sci. Technol. 2003, 37, 2296-2301. [CrossRef] [PubMed]

16. Yin, Z.F.; Wu, L.; Yang, H.G.; Su, Y.H. Recent progress in biomedical applications of titanium dioxide. Phys. Chem. Chem. Phys. 2013, 15, 4844-4858. [CrossRef]

17. Benjamin, M.M.; Lawler, D.F. Water Quality Engineering: Physical/Chemical Treatment Processes; John Wiley \& Sons: Hoboken, NJ, USA, 2013.

18. Gaya, U.I.; Abdullah, A.H. Heterogeneous photocatalytic degradation of organic contaminants over titanium dioxide: A review of fundamentals, progress and problems. J. Photochem. Photobiol. C Photochem. Rev. 2008, 9, 1-12. [CrossRef]

19. Fujishima, A.; Rao, T.N.; Tryk, D.A. Titanium dioxide photocatalysis. J. Photochem. Photobiol. C Photochem. Rev. 2000, 1, 1-21. [CrossRef]

20. Pelaez, M.; de la Cruz, A.A.; Stathatos, E.; Falaras, P.; Dionysiou, D.D. Visible light-activated N-F-codoped $\mathrm{TiO}_{2}$ nanoparticles for the photocatalytic degradation of microcystin-LR in water. Catal. Today 2009, 144, 19-25. [CrossRef]

21. Asahi, R.; Morikawa, T.; Ohwaki, T.; Aoki, K.; Taga, Y. Visible-Light Photocatalysis in Nitrogen-Doped Titanium Oxides. Science 2001, 293, 269-271. [CrossRef]

22. Khan, S.U.M.; Al-Shahry, M.; Ingler, W.B. Efficient Photochemical Water Splitting by a Chemically Modified n- $\mathrm{TiO}_{2}$. Science 2002, 297, 2243-2245. [CrossRef] [PubMed]

23. Bavykin, D.V.; Friedrich, J.M.; Walsh, C. Protonated Titanates and $\mathrm{TiO}_{2}$ Nanostructured Materials: Synthesis, Properties, and Applications. Adv. Mater. 2006, 18, 2807-2824. [CrossRef]

24. Thompson, T.L.; Yates, J.T. Surface Science Studies of the Photoactivation of $\mathrm{TiO}_{2} \mathrm{New}$ Photochemical Processes. Chem. Rev. 2006, 106, 4428-4453. [CrossRef] [PubMed]

25. Sorathiya, K.; Mishra, B.; Kalarikkal, A.; Reddy, K.P.; Gopinath, C.S.; Khushalani, D. Enhancement in Rate of Photocatalysis Upon Catalyst Recycling. Sci. Rep. 2016, 6, 35075. [CrossRef]

26. Lee, K.M.; Lai, C.W.; Ngai, K.S.; Juan, J.C. Recent developments of zinc oxide based photocatalyst in water treatment technology: A review. Water Res. 2016, 88, 428-448. [CrossRef]

27. Chang, Y.-N.; Zhang, M.; Xia, L.; Zhang, J.; Xing, G. The Toxic Effects and Mechanisms of CuO and ZnO Nanoparticles. Materials 2012, 5, 2850-2871. [CrossRef]

28. Sakthivel, S.; Neppolian, B.; Shankar, M.V.; Arabindoo, B.; Palanichamy, M.; Murugesan, V. Solar photocatalytic degradation of azo dye: Comparison of photocatalytic efficiency of $\mathrm{ZnO}$ and $\mathrm{TiO}_{2}$. Sol. Energy Mater. Sol. Cells 2003, 77, 65-82. [CrossRef]

29. Colón, G.; Hidalgo, M.C.; Navío, J.A.; Melián, E.P.; Díaz, O.G.; Rodríguez, J.M.D. Highly photoactive ZnO by amine capping-assisted hydrothermal treatment. Appl. Catal. B Environ. 2008, 83, 30-38. [CrossRef]

30. Hill, J.C.; Choi, K.-S. Effect of Electrolytes on the Selectivity and Stability of n-type $\mathrm{WO}_{3}$ Photoelectrodes for Use in Solar Water Oxidation. J. Phys. Chem. C 2012, 116, 7612-7620. [CrossRef]

31. Hameed, A.; Gondal, M.A.; Yamani, Z.H. Effect of transition metal doping on photocatalytic activity of $\mathrm{WO}_{3}$ for water splitting under laser illumination: Role of 3d-orbitals. Catal. Commun. 2004, 11, 715-719. [CrossRef]

32. Lassoued, A.; Lassoued, M.S.; Dkhil, B.; Ammar, S.; AGadri, A. Photocatalytic degradation of methylene blue dye by iron oxide $\left(\alpha-\mathrm{Fe}_{2} \mathrm{O}_{3}\right)$ nanoparticles under visible irradiation. J. Mater. Sci. Mater. Electron. 2018, 29, 8142-8152. [CrossRef]

33. Calza, P.; Pelizzetti, E.; Brussino, M.; Baiocchi, C. Ion trap tandem mass spectrometry study of dexamethasone transformation products on light activated $\mathrm{TiO}_{2}$ surface. J. Am. Soc. Mass Spectrom. 2001, 12, 1286-1295. [CrossRef]

34. Calza, P.; Pazzi, M.; Medana, C.; Baiocchi, C.; Pelizzetti, E. The photocatalytic process as a tool to identify metabolitic products formed from dopant substances: The case of buspirone. J. Pharm. Biomed. Anal. 2004, 35, 9-19. [CrossRef] [PubMed]

35. Medana, C.; Calza, P.; Giancotti, V.; Bello, F.D.; Pasello, E.; Montana, M.; Baiocchi, C. Horse metabolism and the photocatalytic process as a tool to identify metabolic products formed from dopant substances: The case of sildenafil. Drug Test. Anal. 2011, 3, 724-734. [CrossRef]

36. Gawlik, M.; Trawiński, J.; Skibiński, R. Imitation of phase I metabolism reactions of MAO-A inhibitors by titanium dioxide photocatalysis. Eur. J. Pharm. Sci. 2018, 114, 391-400. [CrossRef] [PubMed] 
37. Ruokolainen, M.; Valkonen, M.; Sikanen, T.; Kotiaho, T.; Kostiainen, R. Imitation of phase I oxidative metabolism of anabolic steroids by titanium dioxide photocatalysis. Eur. J. Pharm. Sci. 2014, 65, 45-55. [CrossRef] [PubMed]

38. Nissilä, T.; Sainiemi, L.; Karikko, M.-M.; Kemell, M.; Ritala, M.; Franssila, S.; Kostiainen, R.; Ketola, R.A. Integrated photocatalytic micropillar nanoreactor electrospray ionization chip for mimicking phase I metabolic reactions. Lab. Chip. 2011, 11, 1470-1476. [CrossRef] [PubMed]

39. Raoof, H.; Mielczarek, P.; Michalow, K.A.; Rekas, M.; Silberring, J. Synthesis of metabolites of paracetamol and cocaine via photooxidation on $\mathrm{TiO}_{2}$ catalyzed by UV light. J. Photochem. Photobiol. B 2013, 118, 49-57. [CrossRef]

40. Medana, C.; Calza, P.; Giancotti, V.; Bello, F.D.; Aragno, M.; Baiocchi, C. Study of the photocatalytic transformation of synephrine: A biogenic amine relevant in anti-doping analysis. Anal. Bioanal. Chem. 2013, 405, 1105-1113. [CrossRef]

41. Ruokolainen, M.; Gul, T.; Permentier, H.; Sikanen, T.; Kostiainen, R.; Kotiaho, T. Comparison of $\mathrm{TiO}_{2}$ photocatalysis, electrochemically assisted Fenton reaction and direct electrochemistry for simulation of phase I metabolism reactions of drugs. Eur. J. Pharm. Sci. 2016, 83, 36-44. [CrossRef]

42. Baillie, T.A.; Rettie, A.E. Role of Biotransformation in Drug-Induced Toxicity: Influence of Intra- and Inter-Species Differences in Drug Metabolism. Drug Metab. Pharm. 2011, 26, 15-29. [CrossRef] [PubMed]

43. Park, K.; Williams, D.P.; Naisbitt, D.J.; Kitteringham, N.R. MPirmohamed, Investigation of toxic metabolites during drug development. Toxicol. Appl. Pharmacol. 2005, 207, 425-434. [CrossRef] [PubMed]

44. Baillie, T.A. Metabolism and Toxicity of Drugs. Two Decades of Progress in Industrial Drug Metabolism. Chem. Res. Toxicol. 2008, 21, 129-137. [CrossRef] [PubMed]

45. Morgan, S.; Grootendorst, P.; Lexchin, J.; Cunningham, C.; Greyson, D. The cost of drug development: A systematic review. Health Policy 2011, 100, 4-17. [CrossRef]

46. Gawlik, M.; Skibiński, R. Identification of new metabolites of vardenafil with the use of HLM and photochemical methods by LC-ESI-HRMS combined with multivariate chemometric analysis. Int. J. Mass Spectrom. 2018, 433, 55-60. [CrossRef]

47. Gawlik, M.; Skibiński, R. Simulation of phase I metabolism reactions of clozapine by HLM and photocatalytic methods with the use of UHPLC-ESI-MS/MS. Biomed. Chromatogr. 2018, 32, 1-8. [CrossRef]

48. Liu, X.; Lu, Y.-F.; Guan, X.; Zhao, M.; Wang, J.; Li, F. Characterizing novel metabolic pathways of melatonin receptor agonist agomelatine using metabolomic approaches. Biochem. Pharmacol. 2016, 109, 70-82. [CrossRef]

49. Bushee, J.L.; Dunne, C.E.; Argikar, U.A. An in vitro approach to investigate ocular metabolism of a topical, selective $\beta 1$-adrenergic blocking agent, Betaxolol. Xenobiotica 2015, 45, 396-405. [CrossRef]

50. Christensen, H. Chlorprothixene and its metabolites in blood, liver and urine from fatal poisoning. Acta Pharmacol. Toxicol. (Copenh.) 1974, 34, 16-26. [CrossRef]

51. Yamahata, T.; Minaki, Y.; Okada, S.; Kohno, R.; Nishikawa, H.; Esumi, Y.; Jin, Y.; Okamura, Y.; Ishizaki, M.; Gunji, S.; et al. Metabolic Fate of Clonidine (V): Metabolism of Clonidine after Subcutaneous Administration of Clonidine to Rats, Dogs and Monkeys and Dermal Application of Clonidine Tape, M-5041T, to Rats. Drug Metab. Pharmacokinet. 1996, 11, 411-420. [CrossRef]

52. Lavrijsen, K.; van Houdt, J.; van Dyck, D.; Hendrickx, J.; Bockx, M.; Hurkmans, R.; Meuldermans, W.; le Jeune, L.; Lauwers, W.; Heykants, J. Comparative metabolism of flunarizine in rats, dogs and man: An in vitro study with subcellular liver fractions and isolated hepatocytes. Xenobiotica Fate Foreign Compd. Biol. Syst. 1992, 22, 815-836. [CrossRef] [PubMed]

53. Wong, Y.C.; Wo, S.K.; Zuo, Z. Investigation of the disposition of loxapine, amoxapine and their hydroxylated metabolites in different brain regions, CSF and plasma of rat by LC-MS/MS. J. Pharm. Biomed. Anal. 2012, 58, 83-93. [CrossRef]

54. Hendrickx, J.; Bockx, M.; Zwijsen, C.; Borgmans, C.; Mannens, G.; Meuldermans, W.; Heykants, J. Location of the hydroxyl functions in hydroxylated metabolites of nebivolol in different animal species and human subjects as determined by on-line high-performance liquid chromatography-diode-array detection. J. Chromatogr. A 1996, 729, 341-354. [CrossRef]

55. Davies, B.J.; Herbert, M.K.; Coller, J.K.; Somogyi, A.A.; Milne, R.W.; Sallustio, B.C. Determination of the 4-monohydroxy metabolites of perhexiline in human plasma, urine and liver microsomes by liquid chromatography. J. Chromatogr. B Analyt. Technol. Biomed. Life Sci. 2006, 843, 302-309. [CrossRef] 
56. Fisher, D.S.; Handley, S.A.; Taylor, D.; Flanagan, R.J. Measurement of quetiapine and four quetiapine metabolites in human plasma by LC-MS/MS. Biomed. Chromatogr. BMC 2012, 26, 1125-1132. [CrossRef] [PubMed]

57. Fleishaker, J.C. Clinical pharmacokinetics of reboxetine, a selective norepinephrine reuptake inhibitor for the treatment of patients with depression. Clin. Pharm. 2000, 39, 413-427. [CrossRef]

58. Grond, S.; Sablotzki, A. Clinical pharmacology of tramadol. Clin. Pharmacokinet. 2004, 43, 879-923. [CrossRef]

59. Gu, X.; Liu, Y.-M.; Yao, T.; Shi, H.-L.; Li, J.; Zhao, Z.; Qin, Y.-C. Identification of Major Metabolites of Salbutamol in Swine Urine and Plasma Using Ultra-High Performance Liquid Chromatography-Electrospray Time of Flight Mass Spectrometry. Chin. J. Anal. Chem. 2014, 42, 1692-1696. [CrossRef]

60. Yamato, C.; Takahashi, T.; Fujita, T. Studies on metabolism of trazodone. III Species differences. Xenobiotica Fate Foreign Compd. Biol. Syst. 1976, 6, 295-306. [CrossRef]

61. von Moltke, L.L.; Greenblatt, D.J.; Granda, B.W.; Duan, S.X.; Grassi, J.M.; Venkatakrishnan, K.; Harmatz, J.S.; Shader, R.I. Zolpidem metabolism in vitro: Responsible cytochromes, chemical inhibitors, and in vivo correlations. Br. J. Clin. Pharmacol. 1999, 48, 89-97. [CrossRef]

62. Becquemont, L.; Mouajjah, S.; Escaffre, O.; Beaune, P.; Funck-Brentano, C.; Jaillon, P. Cytochrome P-450 3A4 and 2C8 Are Involved in Zopiclone Metabolism. Drug Metab. Dispos. 1999, 27, 1068-1073. [PubMed]

63. Frey, H.H.; Scherkl, R. Clorazepate, correlation between metabolism and anticonvulsant activity. Eur. J. Pharmacol. 1988, 158, 213-216. [CrossRef]

(C) 2019 by the authors. Licensee MDPI, Basel, Switzerland. This article is an open access article distributed under the terms and conditions of the Creative Commons Attribution (CC BY) license (http://creativecommons.org/licenses/by/4.0/). 